application to CCDC, 12 Union Road, Cambridge CB21EZ, UK (fax: (+44)1223-336-033; e-mail: deposit@ccdc.cam.ac.uk).

[13] R. A. Leising, J. S. Ohman, K. J. Takeuchi, Inorg. Chem. 1988, 27, 3804-3809.

[14] a) R. E. Shepherd, H. Taube, Inorg. Chem. 1973, 12, 1392-1401; b) S. S. Isied, H. Taube, Inorg. Chem. 1976, 15, 3070-3075.

[15] T. Matsubara, C. Creutz, Inorg. Chem. 1979, 18, 1956-1966.

[16] L. R. Allen, P. R. Craft, B. Durham, J. Walsh, Inorg. Chem. 1987, 26, $53-56$.

[17] M. H. V. Huynh, J. M. Lasker, M. Wetzler, B. Mort, L. F. Szczepura, L. M. Witham, J. M. Cintron, A. C. Marschilok, L. J. Ackerman, R. K. Castellano, D. L. Jameson, M. R. Churchill, A. J. Jircitano, K. J. Takeuchi, J. Am. Chem. Soc. 2001, 123, 8780-8784.

[18] C. A. Bessel, J. A. Margarucci, J. H. Acquaye, R. S. Rubino, J. Crandall, A. J. Jircitano, K. J. Takeuchi, Inorg. Chem. 1993, 32, $5779-5784$

[19] a) Typically, rates of aqua-ligand exchange in ruthenium(II) and ruthenium(III) complexes range from $1 \times 10^{-6} \mathrm{M}^{-1} \mathrm{~s}^{-1}$ to $1 \times$ $10^{-2} \mathrm{M}^{-1} \mathrm{~s}^{-1}$; b) L. Mønsted, O. Mønsted, Coord. Chem. Rev. 1989, $94,109-150$.

\section{Homogeneous Reactions in Supercritical Carbon Dioxide Using a Catalyst Immobilized by a Microporous Silica Membrane}

Leo J. P. van den Broeke,* Earl L. V. Goetheer, Arjan W. Verkerk, Elwin de Wolf, Berth-Jan Deelman, Gerard van Koten, and Jos T. F. Keurentjes

Although homogeneous catalysis offers many advantages over heterogeneous catalysis in terms of catalytic selectivity and activity, the difficult separation of the catalyst from the products and the use of environmentally harmful organic solvents are two major drawbacks. ${ }^{[1,2]}$ The problem of catalyst separation has been addressed by several groups, and a number of new concepts for immobilization of homogeneous catalysts have been developed. ${ }^{[3]}$ With respect to the use of more environmentally friendly solvents, the application of high-density gases such as supercritical carbon dioxide $\left(\mathrm{scCO}_{2} ; T_{\mathrm{c}}=304.2 \mathrm{~K}\right.$ and $\left.P_{\mathrm{c}}=73.8 \mathrm{bar}\right)$ has some clear advantages. ${ }^{[2,4]}$ Supercritical solvents are completely miscible with gaseous reagents, and, therefore, avoid possible diffusion limitation in gas-liquid reactions. An important issue for successful operation of homogeneous catalysis in $\mathrm{scCO}_{2}$ is the solubility of the catalyst, which can be achieved by attaching perfluoroalkyl groups to the ligands. ${ }^{[5]}$

Herein, we present a solution that overcomes these drawbacks. We employ a continuous reactor for homogeneous catalysis in $\mathrm{scCO}_{2}$ that allows an integrated catalyst separation by immobilization of a perfluoroalkylated catalyst on one side of a microporous silica membrane. The low cohesive energy density of perfluoroalkyl groups is used to realize the required solubility of the catalyst in $\mathrm{scCO}_{2}$, and simultaneously the increased size ensures effective retention of the catalyst in the membrane reactor. The reactants and products, which are also dissolved in the $\mathrm{scCO}_{2}$, can diffuse through the membrane.

The principle is demonstrated by using a $(1 \mathrm{H}, 1 \mathrm{H}, 2 \mathrm{H}, 2 \mathrm{H}$ perfluoroalkyl)dimethylsilyl-substituted derivative of Wilkinson's catalyst, $\mathbf{1}^{[6]}$ and a supported microporous silica

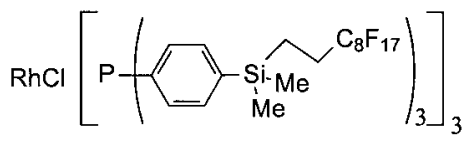

1

membrane with an average pore size of $0.6 \mathrm{~nm} . .^{[7]}$ The mechanical strength of ceramic silica membranes allows the use of relatively harsh reaction conditions. As a model reaction the hydrogenation of 1-butene was first carried out in $\mathrm{scCO}_{2}$ in a batch reactor ${ }^{[8]}$ at 200 bar and $353 \mathrm{~K}$. The catalyst 1 was prepared in situ from $[\mathrm{RhCl}(\operatorname{cod})]_{2}(\operatorname{cod}=$ cis,cis-1,5-cyclooctadiene) and six equivalents of $\mathrm{P}(p-(\mathrm{Si}-$ $\left.\left.\mathrm{Me}_{2} \mathrm{CH}_{2} \mathrm{CH}_{2} \mathrm{C}_{8} \mathrm{~F}_{17}\right) \mathrm{C}_{6} \mathrm{H}_{4}\right)_{3}$. In the batch reactor the turnover frequency (TOF) at $25 \%$ conversion was found to be $9400 \mathrm{~h}^{-1}$. The high solubility of hydrogen in $\mathrm{scCO}_{2}$, as compared to the solubility in conventional solvents, ${ }^{[6]}$ is responsible for the 10 fold higher activity. For the sake of comparison, the solublity of hydrogen in toluene is $2.7 \mathrm{~mm}$ (at 1 bar and $298 \mathrm{~K}$ ) and in fluorous solvents, like $c-\mathrm{C}_{6} \mathrm{~F}_{11} \mathrm{CF}_{3}$, it is $6.1 \mathrm{~mm}$ (at 1 bar and $298 \mathrm{~K})$.

In the continuous membrane set-up (Figure 1), permeation and reaction experiments were typically conducted with a feed pressure of $200 \mathrm{bar}$ and a transmembrane pressure between 0.5 and 10 bar. ${ }^{[9]}$ Experiments have been performed with different pressure differences across the membrane to study the effect of the residence time on the conversion.

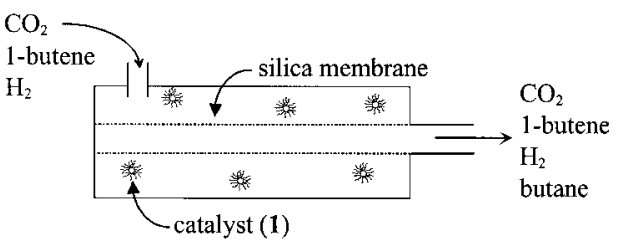

Figure 1. Continuous reaction and separation concept. The membrane reactor is operated in a dead-end configuration.

Up to a feed side pressure of 200 bar high fluxes of carbon dioxide were obtained through the microporous membrane. An overview of the characteristics of the membrane reactor is given in Table 1. 
Table 1. Characteristics of the membrane reactor.

\begin{tabular}{ll}
\hline Property & \\
\hline thickness selective silica layer & $200 \mathrm{~nm}$ \\
length membrane & $0.30 \mathrm{~m}$ \\
outer diameter ceramic membrane & $0.014 \mathrm{~m}$ \\
membrane reactor volume & $35.0 \mathrm{~mL}$ \\
$\mathrm{CO}_{2}$ permeance ${ }^{[\mathrm{a}]}(200 \mathrm{bar}, 353 \mathrm{~K})$ & $3.0 \times 10^{-3} \mathrm{~mol} \mathrm{~m}^{-2} \mathrm{~s}^{-1} \mathrm{bar}^{-1}$
\end{tabular}

[a] Flux divided by the pressure difference across the membrane.

In the continuous process ${ }^{[10]}$ about two permeated reactor volumes were needed to reach a constant conversion of about $40 \%$ (Figure 2). In the experiment a pressure difference of

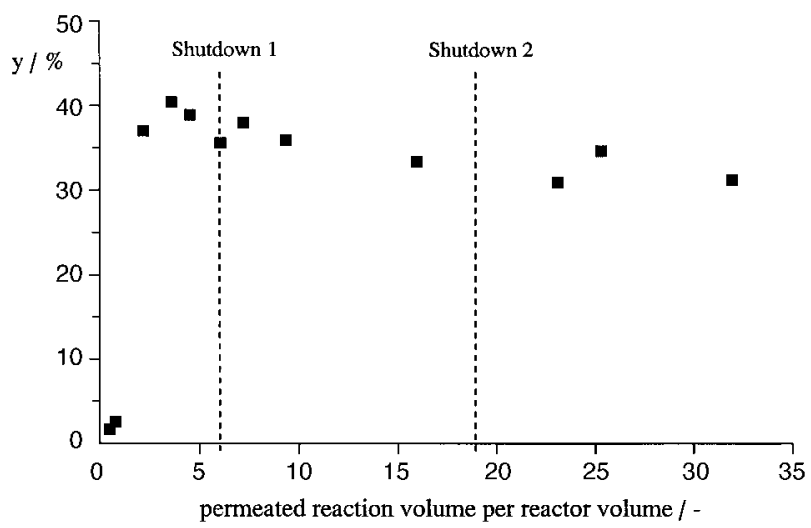

Figure 2. Conversion, $y[\%]$, of 1-butene to butane versus permeated volume per reactor volume, for the continuous reaction/separation process.

3 bar is applied, and this corresponds to a residence time of $62 \mathrm{~min}$. The TOF, based on the initial amount of catalyst added, is $4000 \mathrm{~h}^{-1}$, which is about $60 \%$ lower than in the batch experiment $\left(\mathrm{TOF}=9400 \mathrm{~h}^{-1}\right)$. Overnight the pressure of the system was reduced to 60 bar, leaving no pressure difference between the feed and the permeate side of the membrane. During the depressurization of the membrane reactor the catalyst precipitated and no further reaction occurred. The precipitated catalyst was used for a new cycle by pressurization of the membrane reactor. The shutdown procedure was carried out twice to check the stability of the catalyst under those conditions. At the start of a new cycle, the system was first pressurized to 200 bar for $2 \mathrm{~h}$ to dissolve the catalyst before creating a transmembrane pressure difference. At the end of the third run a conversion of about $33 \%$ was obtained $\left(\mathrm{TOF}=3000 \mathrm{~h}^{-1}\right)$. An overall turnover number of about $1.2 \times$ $10^{5}$ was obtained (in $32 \mathrm{~h}$ ), and a total of 32 reactor volumes had permeated through the membrane. The overall operating time, including start-ups, reaction cycles, and shutdowns, was approximately $75 \mathrm{~h}$.

In Figure 2 an $18 \%$ decrease in conversion is observed (from $40 \%$ to $33 \%$ ). Analysis of the permeate stream by UV/ Vis spectroscopy ${ }^{[11]}$ and by inductively coupled plasma atomic absorption spectrometry (ICP-AAS) showed that there was no transport of the catalyst or of the free ligand through the membrane; thus, it can be concluded that complete retention of $\mathbf{1}$ occurred. Even if the decrease in conversion would have been caused by leaching of the catalyst, the retention of the catalyst per permeated reactor volume is still over $99 \%$. The latter appears highly unlikely since the size of $\mathbf{1}$, as obtained from a MMFF94 molecular mechanics structural optimization (4 nm) and dynamic light scattering $\left(2 \mathrm{~nm}\right.$ in $\left.c-\mathrm{C}_{6} \mathrm{~F}_{11} \mathrm{CF}_{3}\right)$, was found to be much larger than the average pore size of the membrane $(0.6 \mathrm{~nm})$. Oxidation of $\mathbf{1}$ due to residual traces of oxygen in the carbon dioxide or the feed is a more likely explanation for the observed decrease in activity.

In conclusion, we have demonstrated the successful application of membrane separation technology for the immobilization of homogeneous catalysts in a continuous process using a supercritical solvent. It is clear that the methodology presented here could be highly relevant for the further development of clean chemical processes based on homogeneous catalysis carried out in environmentally friendly highdensity gases.

Received: July 5, 2001 [Z17434]

[1] P. G. Jessop, T. Ikariya, R. Noyori, Chem. Rev. 1999, 99, 475.

[2] D. Adams, Nature 2000, 407, 938.

[3] M. G. L. Petrucci, A. K. Kakkar, Adv. Mater. 1996, 8, 251; J. W. Knapen, A. W. van der Made, J. C. Wilde, P. W. N. M. van Leeuwen, P. Wijkens, D. M. Grove, G. van Koten, Nature 1994, 372, 659; W. A. Herrmann, C. W. Kohlpainter, Angew. Chem. 1993, 105, 1588; Angew. Chem. Int. Ed. Engl. 1993, 32, 1524; E. de Wolf, G. van Koten, B.-J. Deelman, Chem. Soc. Rev. 1999, 28, 37.

[4] Chemical synthesis using supercritical fluids (Eds.: P. G. Jessop, W. Leitner), Wiley-VCH, Weinheim, 1999; S. L. Wells, J. DeSimone, Angew. Chem. 2001, 113, 534; Angew. Chem. Int. Ed. 2001, 40, 518; B. Lin, A. Akgerman, Ind. Eng. Chem. Res. 2001, 40, 1113.

[5] S. Kainz, D. Koch, W. Baumann, W. Leitner, Angew. Chem. 1997, 109, 1699; Angew. Chem. Int. Ed. Engl. 1997, 36, 1628.

[6] B. Richter, A. L. Spek, G. van Koten, B.-J. Deelman, J. Am. Chem. Soc. 2000, 122, 3945; B. Richter, E. de Wolf, G. van Koten, B.-J. Deelman, J. Org. Chem. 2000, 65, 3885.

[7] M. K. Koukou, N. Papayannakos, N. C. Markatos, M. Bracht, H. M. Veen, A. Roskam, J. Membr. Sci. 1999, 155, 241.

[8] The batch reactor, with a volume of $26 \mathrm{~mL}$, consists of two saffire windows for UV/Vis monitoring. The volume of the reactor can be controlled with a piston, which assures sampling without disturbing the reaction conditions. The concentration of 1 was $1.0 \times 10^{-6} \mathrm{~mol} \mathrm{~L}^{-1}$, and 1-butene and hydrogen were present in a concentration of 0.02 and $0.08 \mathrm{~mol} \mathrm{~L}^{-1}$, respectively, at a total pressure of $200 \mathrm{bar}$.

[9] For the permeation experiments and the hydrogenation reaction in the membrane reactor the same high-pressure set-up was used. The catalyst was first synthesized in situ in a high-pressure reactor. The catalyst was introduced into the system by gently flushing $\mathrm{CO}_{2}$ through the high-pressure reactor. The reaction was started by the addition of the 1-butene and hydrogen to the membrane module. The membrane was pressurized at the feed and permeates side up to 200 bar with the reaction mixture, by using a LKB HPLC pump and was monitored by a Meyvis $802-\mathrm{C}$ pressure module. The permeate needle valve was opened to create a transmembrane pressure varying between 0.5 to 10 bar. The composition of the permeate was monitored by GC and by GC-MS.

[10] During the continuous reaction experiments the concentration of $\mathbf{1}$ was $1.0 \times 10^{-6} \mathrm{~mol} \mathrm{~L}^{-1}$, and 1-butene and hydrogen were present in a concentration of 0.02 and $0.08 \mathrm{~mol} \mathrm{~L}^{-1}$, respectively.

[11] A $2.2 \mathrm{~mL}$ high-pressure viewing cell was used in combination with a spectrophotometer; measurements recorded at 280 and $410 \mathrm{~nm}$. 